$\begin{array}{cc}\text { ACADEMIA ROMÂNĂ } & \text { Rev. Roum. Chim., } \\ & \text { Revis, 64(11), 927-934 } \\ \text { heve Roumaine de Chimie } & \text { DOI: 10.33224/rrch.2019.64.11.01 } \\ \text { http://web.icf.ro/rrch/ } & \end{array}$

\title{
BIPYRIDINIUM CHLORIDE SUPPORTED RICE HUSK SILICA: AN EFFICIENT NANOCOMPOSITE FOR THE ONE-POT PREPARATION OF SPIROOXINDOLE PYRAN AND 2-AMINO-4H-CHROMENE DERIVATIVES ${ }^{* *}$
}

\author{
Ali Reza KIASAT, ${ }^{*}$ a Sheida HAMID ${ }^{\mathrm{a}}$ and Seyyed Jafar SAGHANEZHAD ${ }^{\mathrm{b}}$ \\ ${ }^{a}$ Chemistry Department, Faculty of Sciences, Shahid Chamran University of Ahvaz, Ahvaz 61357-4-3169, Iran. \\ ${ }^{\mathrm{b}}$ ACECR-Production Technology Research Institute, Ahvaz, Iran
}

\begin{abstract}
In this paper, rice-husk-silica supported n-propyl bipyridinium chloride (RHPrBPCl) has been prepared as a heterogeneous catalyst. RHPrBPCl has been successfully applied in the one-pot preparation of spirooxindole pyran and 2-amino4H-chromene derivatives. The catalyst was characterized with FT-IR, SEM, and TGA analyses. This methodology offers several advantages including easy work-up procedure, high yields of the products, short reaction times, recyclable catalyst, and green reaction medium.
\end{abstract}

Rice Husk
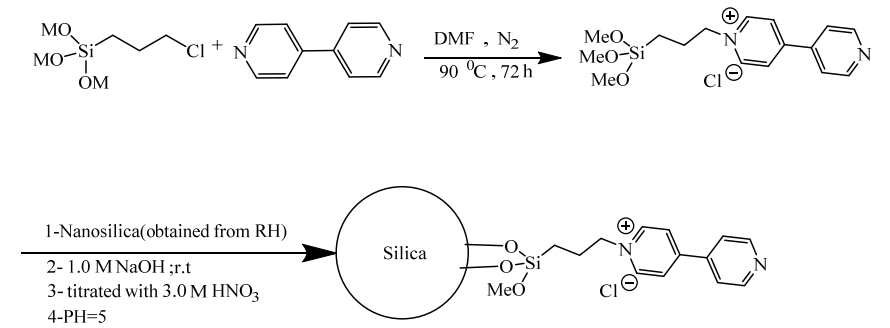

\section{INTRODUCTION}

Organic-chemical synthesis performed through one-pot, tandem, domino or cascade reactions have become a significant area of research in organic chemistry since such processes improve atom economy. Multi-component reactions (MCRs) are defined as one-pot processes that three or more substrates combine either simultaneously, or through a sequential addition procedure that does not require any change of solvent. Recently, total synthesis of natural products, and medicinal heterocyclic compounds, have been performed via MCRs strategy due to their simplicity, higher yield of the products, and lower reaction times. ${ }^{1,2}$

Quite recently nanoparticle assisted synthesis has been investigated due to their higher efficiencies, facile recovery and recyclability. 3,4

2-Amino-chromene derivatives are active moiety of many naturally occurring products. They can also widely be utilized as cosmetics, pigments and potential biodegradable agrochemicals. ${ }^{5}$ These compounds have been of interest from the medicinal chemist point of view for many years. Fused chromenes are biologically active compounds with a wide spectrum of activities such as antimicrobial, ${ }^{6}$ mutagenicitical, ${ }^{7}$ antiviral, ${ }^{8}$ antiproliferative, ${ }^{9}$ sex pheromonal, ${ }^{10}$ antitumoral ${ }^{11}$ and central nervous system activities. ${ }^{12}$

The indole nucleus is a common and important feature of a variety of natural products and medicinal agents. Compounds carrying the indole moiety exhibit antibacterial and antifungal activities. ${ }^{13}$ Furthermore, it has been reported that spiroindoline derivatives possess enhanced biological activity. ${ }^{14}$ The spirooxindole system is the core structure of many pharmacological agents and natural alkaloids. ${ }^{15}$ Quite recently Spirooxindoles have been reviewed as Promising scaffolds for anticancer agents. ${ }^{16}$ Alum, ${ }^{17}$

\footnotetext{
${ }^{*}$ Corresponding author: akiasat@scu.ac.ir

${ }^{* *}$ Supplementary information on http: //web.icf.ro/rrch/ or http: //revroum.lew.ro/
} 
ethylenediaminediacetate, ${ }^{18}$ L-proline, ${ }^{19}$ indium(III) chloride ${ }^{20}$ sodium stearate, ${ }^{21}$ tetrabutyl ammonium bromide, ${ }^{22}$ gold(III) chloride, ${ }^{23}$ 1-butyl-3-methylimidazolium tetrafluoroborate, ${ }^{24}$ and cupreine $^{25}$ are catalysts which have been proposed for the preparation of Spirooxindole pyran derivatives.

Cetyltrimethylammonium chloride/bromide ${ }^{26,27}$ chitosan, ${ }^{28} \mathrm{~K}_{3} \mathrm{PO}_{4},{ }^{29} \mathrm{~K}_{2} \mathrm{CO}_{3},{ }^{30} \mathrm{Na}_{2} \mathrm{CO}_{3},{ }^{31}$ nanosized $\mathrm{MgO},{ }^{32}$ heteropolyacid, ${ }^{33} \mathrm{TiCl}_{4},{ }^{34}$ methane sulfonic acid, $^{35} \quad[\mathrm{BMIm}] \mathrm{BF}_{4},{ }^{36}$ DBU, ${ }^{37}$ and piperidine, ${ }^{38}$ are among those catalysts which have been proposed for the preparation of 2-amino- $4 \mathrm{H}$ chromene derivatives.

While such methods have facilitated the synthesis of these derivatives, they showed varying degrees of success as well as limitations such as protracted reaction times, low yields, use of toxic solvents, and expensive catalysts. Thus novel methodologies with green viewpoint are still needed.

In continuation of our previous effort for the synthesis of new catalysts and their application in organic methodology ${ }^{39,40}$ herein we introduce a novel nanocomposite, rice-husk-silica supported npropyl bipyridinium chloride (RHPrBPCl), for the one-pot preparation of spirooxindole pyran and 2-amino-4H-chromene derivatives (Scheme 1,2).

\section{RESULTS AND DISCUSSION}

\section{Application of RHPrBPCl as a nanocatalyst in the one-pot preparation of spirooxindole pyran derivatives}

At first, RHPrBPCl was prepared according to the procedure (scheme S1). The catalyst was characterized with FT-IR, SEM and TGA analyses. The successful loading of the bipyridinium moiety was confirmed with FT-IR. In the FT-IR spectrum of $\mathrm{RHPrBPCl}$, other than $\mathrm{RH}-\mathrm{SiO}_{2}$ peaks, characteristic peaks of propyl bipyridinium chloride moiety is observed at 1400, 1480 and $1545 \mathrm{~cm}^{-1}$ (Figs. S1 and S2). In the SEM analysis, the nano-agglomerated particles are observed (Fig. S3). According to TGA analysis the decomposition of the organic constituents of the nanocomposite and its surface $\mathrm{OH}$, was occurred in the region of $280-450{ }^{\circ} \mathrm{C}$ (Fig. S3).

Due to the free pyridinic moiety, the catalyst is granted basicity so that it is capable of catalyzing base-catalyzed reactions. For the beginning, spirooxindole pyrans (Scheme 1) were chosen as synthetic targets, due to their importance and their numerous pharmacological properties. For the optimization of the reaction conditions and also evaluation of the catalytic activity of RHPrBPCl, a model reaction consisting isatin $(1 \mathrm{mmol})$, dimedone $(1 \mathrm{mmol})$ and malononitrile $(1.2 \mathrm{mmol})$ in water under reflux conditions was conducted. It was found out that the reaction was slow in the absence of the basic catalyst even after several hours. We were fortunate to see that the reaction is completed in the presence of RHPrBPCl in a short time. $0.05 \mathrm{~g}$ of the catalyst and the ratio of $1: 1: 1.2$ of dimedone, isatin and malononitile were chosen as the optimized reaction conditions.

Following this reaction other spirooxindole pyran derivatives were prepared (Scheme 3).
A<smiles></smiles>

1a-e
2

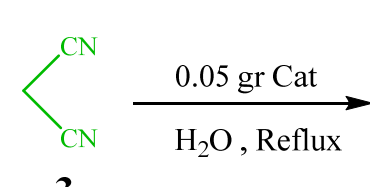

3

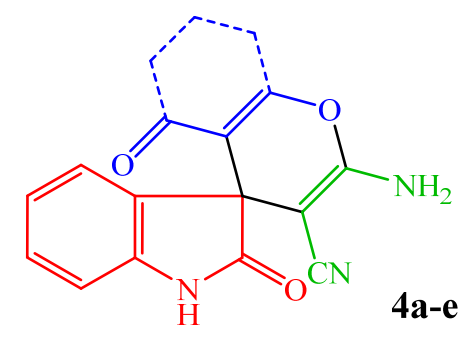<smiles>CC1(C)CC(=O)CC(=O)C1</smiles>

$1 \mathbf{a}$<smiles>Cc1cc(O)cc(=O)o1</smiles>

$1 \mathbf{b}$<smiles>O=c1cc(O)c2ccccc2o1</smiles>

1c<smiles>Oc1cccc2ccccc12</smiles>

1d<smiles>Oc1ccc2ccccc2c1</smiles>

1e

Scheme 1 - One-pot preparation of spirooxindole pyran derivatives in the presence of RHPrBPCl. 


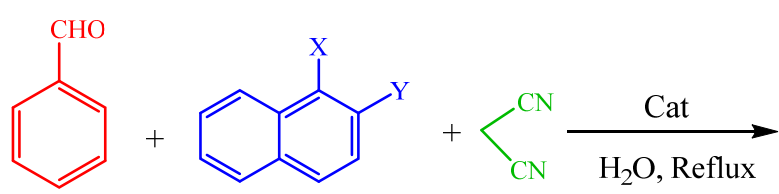<smiles>N#CC1=C(N)Oc2c(ccc3ccccc23)C1c1ccccc1</smiles>

7a-i<smiles>N#CC1=C(N)Oc2ccc3ccccc3c2C1c1ccccc1</smiles>

8a-i

\section{6a: $X=O H, Y=H ;$
6b: $X=H, Y=O H$}

Scheme 2 - One-pot preparation of 2-amino-4H-chromene derivatives in the presence of RHPrBPCl.

Table 1

Optimization of the reaction of isatin, malononitrile and dimedone in the presence of RHPrBPCl

\begin{tabular}{|c|c|c|c|c|c|}
\hline Entry & Catalyst (g) & Temp. $\left({ }^{\circ} \mathrm{C}\right)$ & Solvent & Time. (min) & Yield (\%) \\
\hline 1 & - & Reflux & Water & 180 & 10 \\
\hline 2 & 0.01 & Reflux & Water & 60 & 40 \\
\hline 3 & 0.03 & Reflux & Water & 60 & 70 \\
\hline 4 & 0.05 & Reflux & Water & 10 & 93 \\
\hline 5 & 0.07 & Reflux & Water & 15 & 90 \\
\hline 6 & 0.05 & 80 & Solvent-free & 60 & 35 \\
\hline 7 & 0.05 & Reflux & Ethanol & 60 & 70 \\
\hline 8 & 0.05 & Reflux & Ethanol-Water & 60 & 70 \\
\hline 9 & 0.05 & Reflux & DCM & 60 & 35 \\
\hline
\end{tabular}
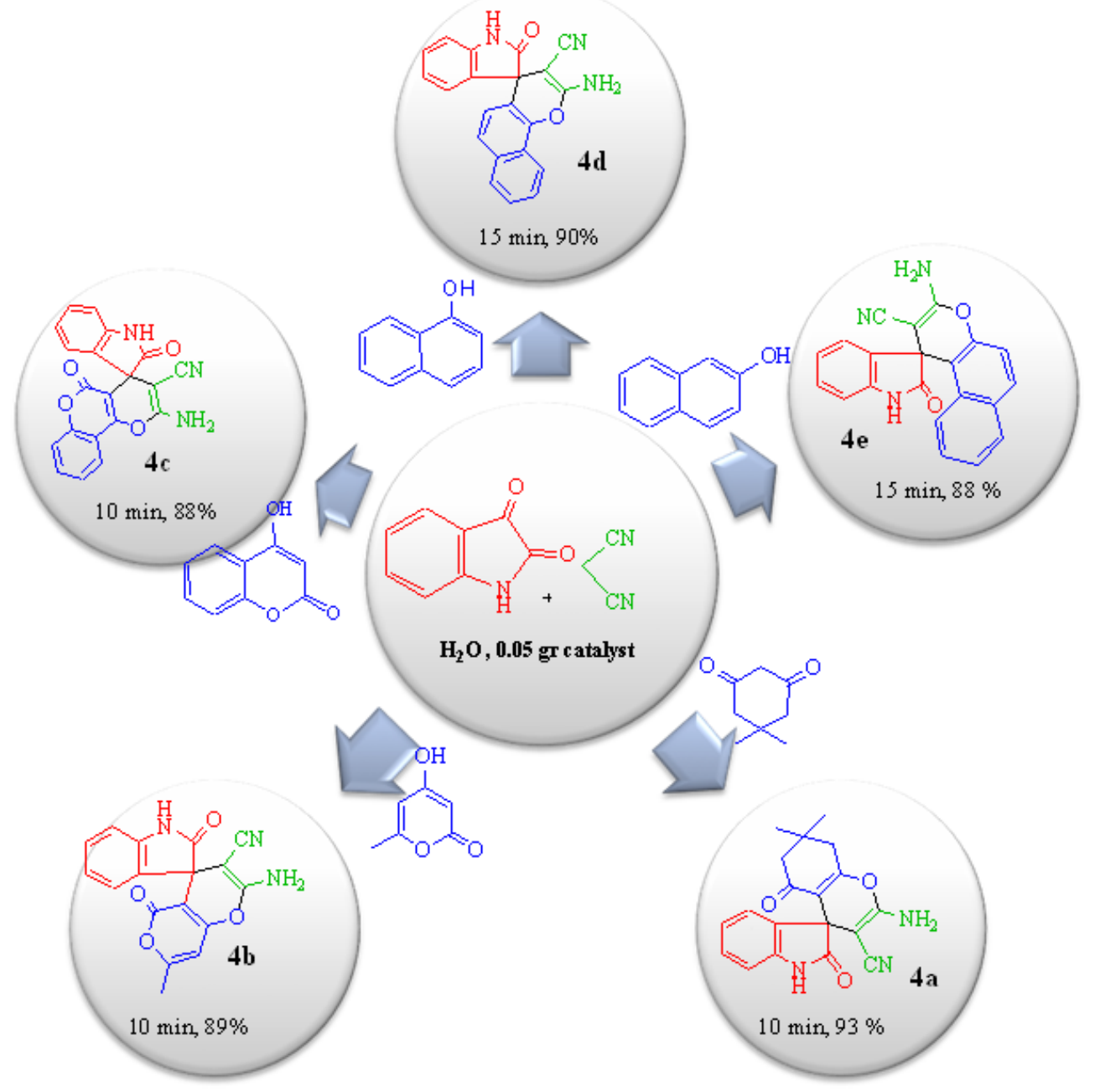

Scheme 3 - One-pot preparation of spirooxindole pyran derivatives in the presence of RHPrBPCl. 


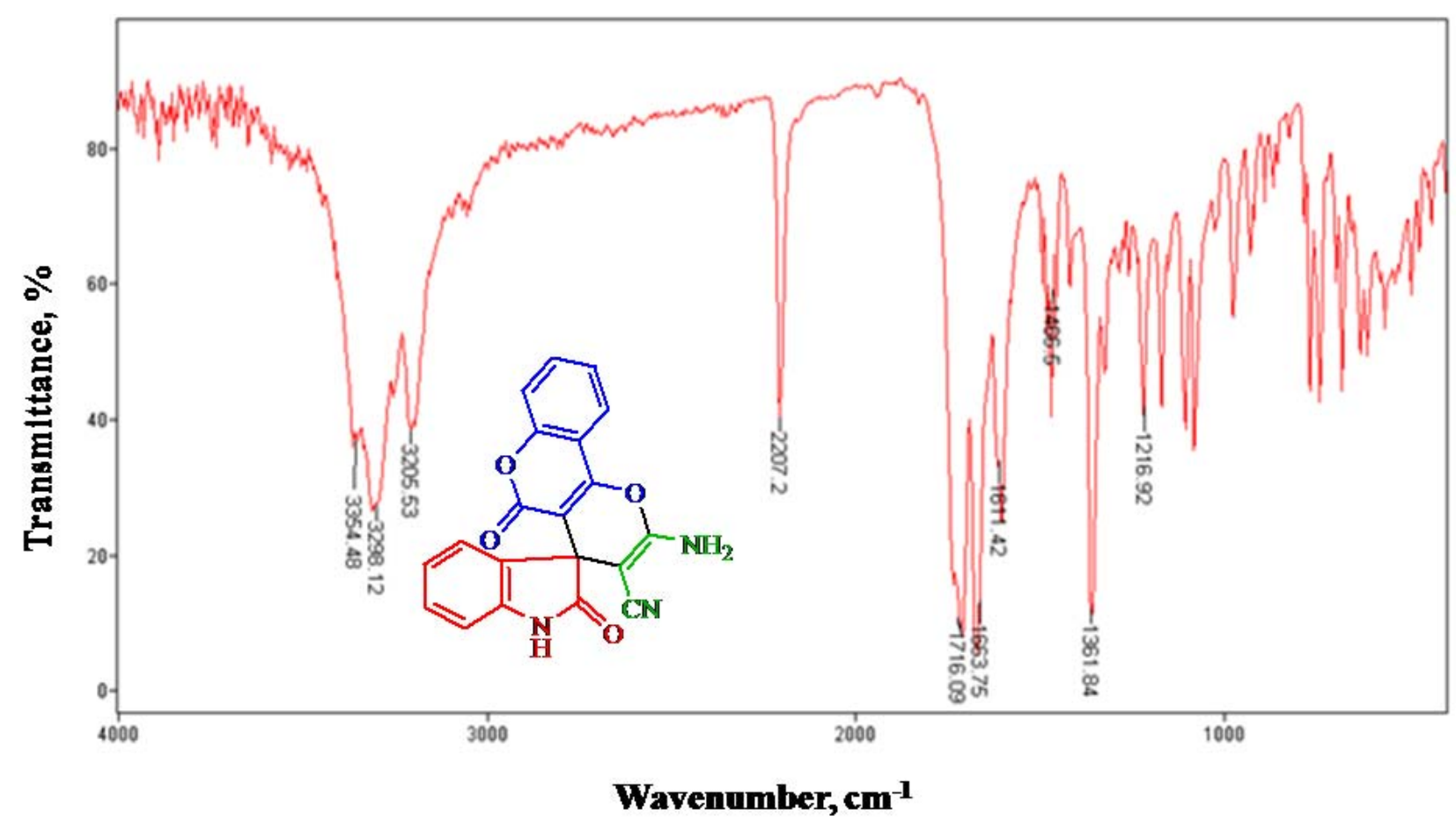

Fig. 1 - FT-IR spectrum of a spirooxindole derivative.

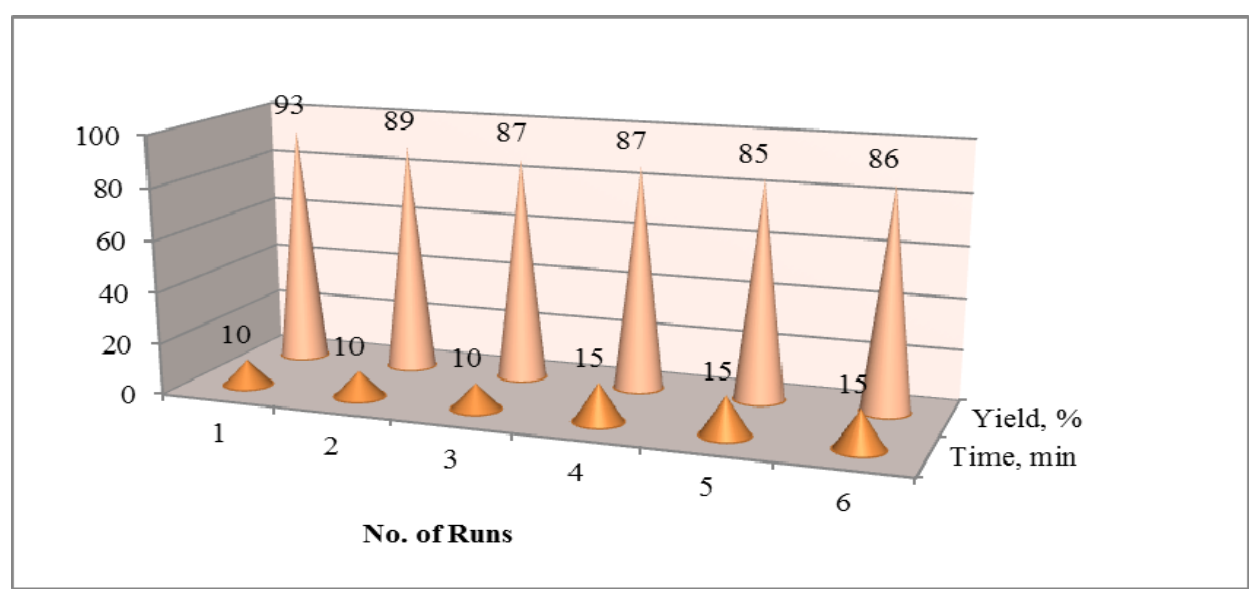

Fig. 2 - Recyclability of RHPrBPCl in the reaction of isatin, malononitrile and dimedone.

According to Scheme 3, all the products were prepared in short reaction time and high yield. Characterization of the products were conducted via FT-IR, ${ }^{1} \mathrm{H}$ NMR and ${ }^{13} \mathrm{C}$ NMR analyses. It should be mentioned that a strong stretching peak of $-\mathrm{CN}$ group is evident at about $2200 \mathrm{~cm}^{-1}$ and two bands in $3200-3450 \mathrm{~cm}^{-1}$ region, due to the asymmetrical $\mathrm{N}-\mathrm{H}$ stretch and the symmetrical $\mathrm{N}-\mathrm{H}$ stretch of the $-\mathrm{NH}_{2}$ group.

It should be noted that the chemical shift of $-\mathrm{CN}$ group is about $110-120 \mathrm{ppm}$ in ${ }^{13} \mathrm{C} \mathrm{NMR}$ spectrum.

The aim of utilizing a heterogeneous catalyst in a reaction is its recyclability other than its benefits. The recyclability of RHPrBPCl was checked for
6 runs in a model reaction (Fig. 2). It can be concluded from the diagram that the efficiency of $\mathrm{RHPrBPCl}$ is slowly decreased after 6 times of reuse.

\section{Application of RHPrBPCI as a nanocatalyst in the one-pot preparation of 2-amino-4H-chromene derivatives}

According to the successful preparation of spirooxindole derivatives, it was decided to apply $\mathrm{RHPrBPCl}$ in the one pot preparation of 2-amino$4 \mathrm{H}$-chromene derivatives by the same manner as before. In this regard, the reaction of $\alpha$-naphthol or 
$\beta$-naphthol, aromatic aldehydes, malononitrile and RHPrBPCl $(0.05 \mathrm{~g})$ in water at reflux conditions were conducted. The 2-amino-4H-chromene derivatives were prepared in short reaction time and high yield (Table 2).
The products were characterized with FT-IR, ${ }^{1} \mathrm{H}$ NMR and ${ }^{13} \mathrm{C}$ NMR analyses. The strong stretching peak of $-\mathrm{CN}$ group is evident at about $2200 \mathrm{~cm}^{-1}$ and two bands of the $-\mathrm{NH}_{2}$ group in $3200-3450 \mathrm{~cm}^{-1}$ region.

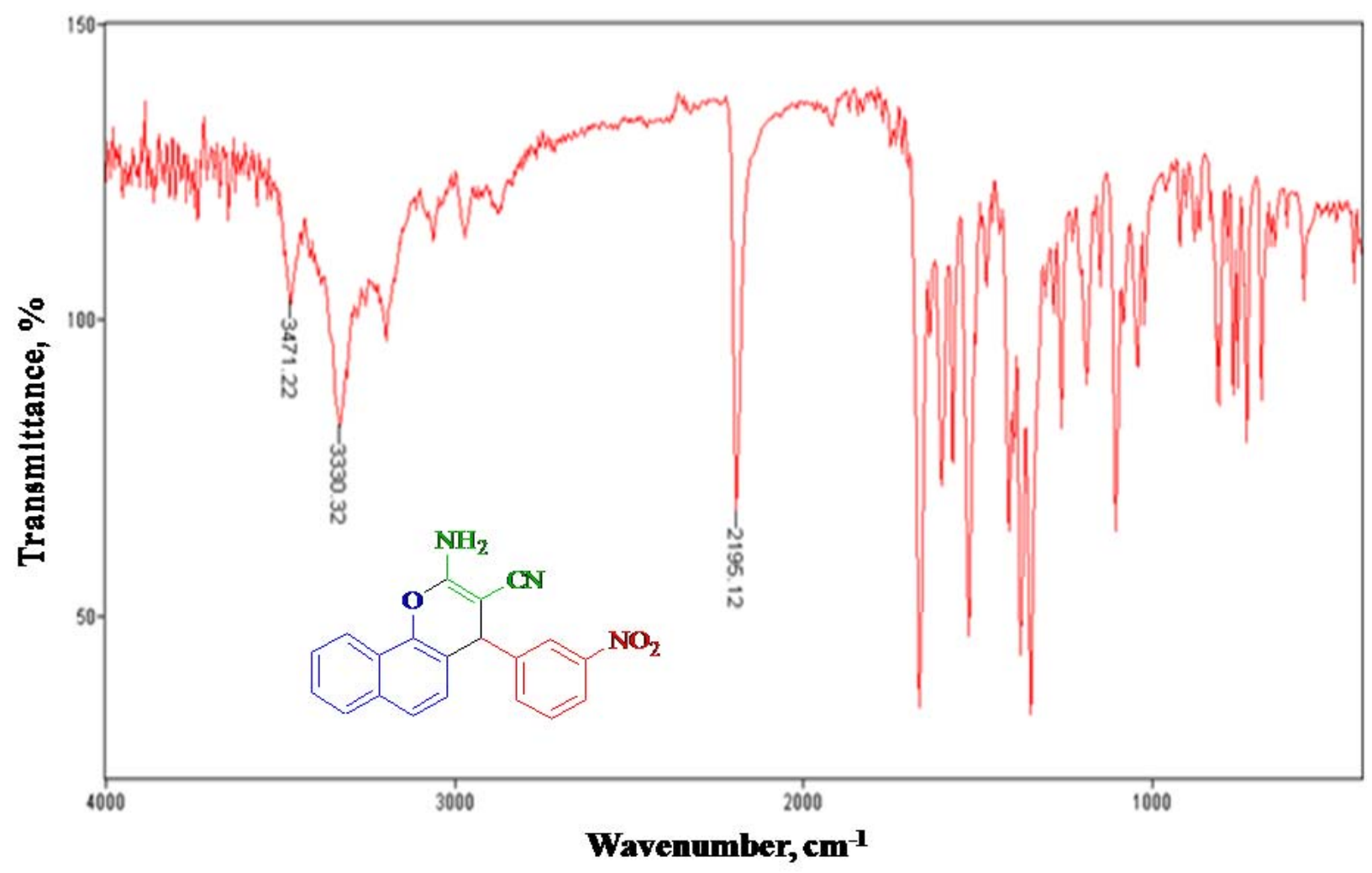

Fig. 3 - FT-IR spectrum of a spirooxindole derivative.

Table 2

One-pot preparation of 2-amino-4H-chromene derivatives in the presence of $\mathrm{RHPrBPCl}$ from the three component reaction of aromatic aldehydes, malononitrile and $\alpha$ or $\beta$-naphthol at $100^{\circ} \mathrm{C}$ in water

\begin{tabular}{c|c|c|c|c|c}
\hline Entry & $\mathrm{R}$ & Naphthol & Product & Time (min) & Yield (\%) \\
\hline 1 & $\mathrm{H}$ & $\alpha$ & $\mathbf{7 a}$ & 13 & 94 \\
2 & $4-\mathrm{NO}_{2}$ & “ & $\mathbf{7 b}$ & 8 & 96 \\
3 & $3-\mathrm{NO}_{2}$ & “ & $\mathbf{7 c}$ & 15 & 90 \\
4 & $4-\mathrm{Cl}$ & $\mathbf{7 d}$ & 15 & 88 \\
5 & $3-\mathrm{OMe}$ & “ & $\mathbf{7 e}$ & 30 & 87 \\
6 & $4-\mathrm{Me}$ & “ & $\mathbf{7 f}$ & 30 & 90 \\
7 & $4-\mathrm{OMe}$ & $\mathbf{7 g}$ & 33 & 87 \\
8 & $3-\mathrm{Cl}$ & $\mathbf{7 h}$ & 20 & 85 \\
9 & $2-\mathrm{Cl}$ & $\mathbf{7 i}$ & 20 & 84 \\
10 & $\mathrm{H}$ & $\mathbf{8 a}$ & 15 & 92 \\
11 & $4-\mathrm{NO} 2$ & $\mathbf{8 b}$ & 10 & 95 \\
12 & $3-\mathrm{NO}_{2}$ & “ & $\mathbf{8 c}$ & 15 & 89 \\
13 & $4-\mathrm{Cl}$ & $\mathbf{8 d}$ & 20 & 87 \\
14 & $3-\mathrm{OMe}$ & “ & $\mathbf{8 e}$ & 30 & 88 \\
15 & $4-\mathrm{Me}$ & “ & $\mathbf{8 f}$ & 35 & 90 \\
16 & $4-\mathrm{OMe}$ & $\mathbf{8 g}$ & 35 & 89 \\
17 & $3-\mathrm{Cl}$ & $\mathbf{8 h}$ & 25 & 85 \\
18 & $2-\mathrm{Cl}$ & $\mathbf{8 i}$ & 25 & 85 \\
\hline
\end{tabular}




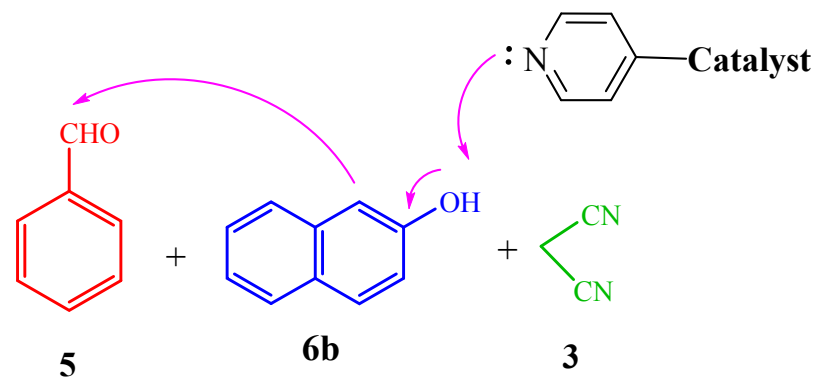<smiles>N#CC1=C(N)Oc2ccc3ccccc3c2C1c1ccccc1</smiles>
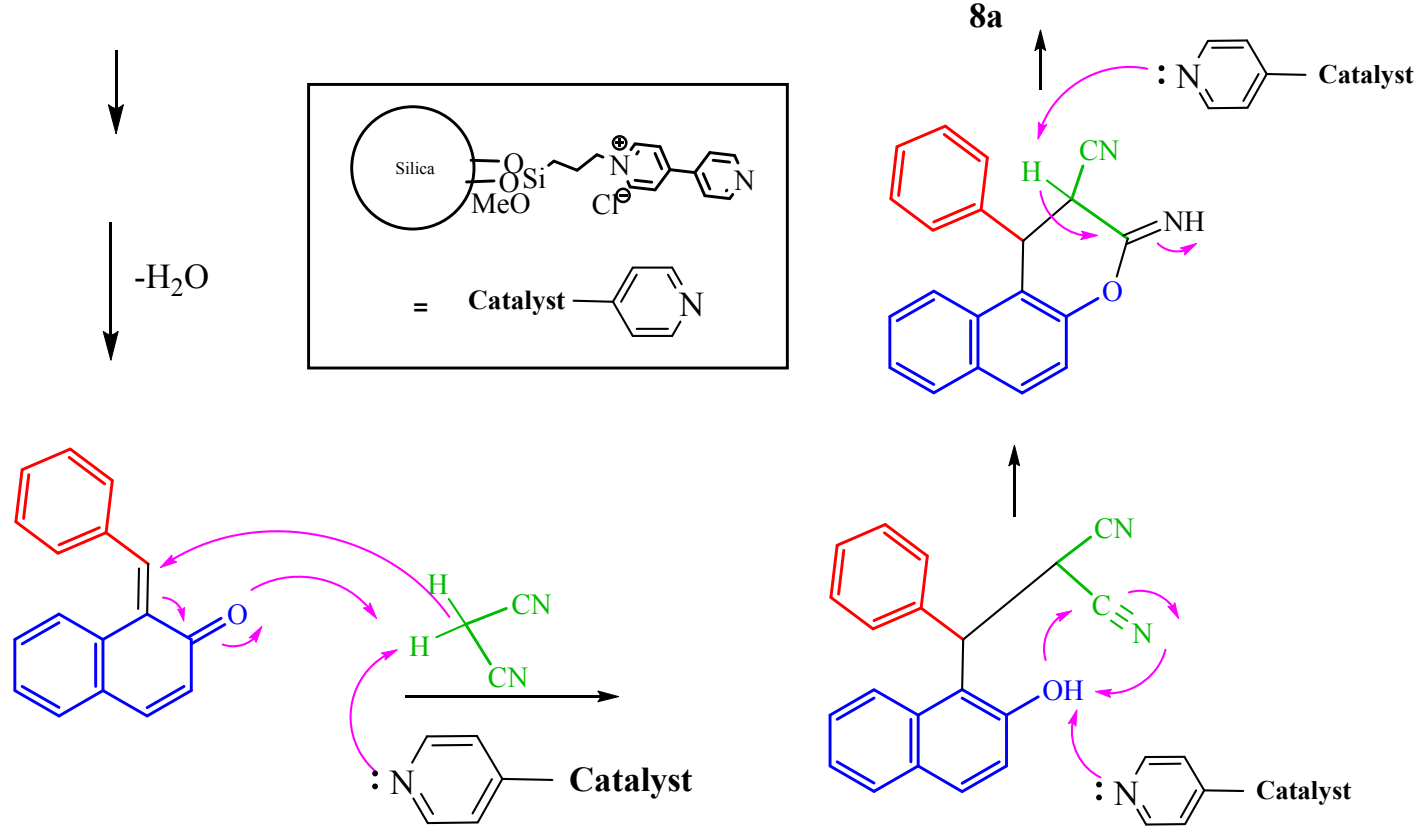

Fig. 4 - The postulated mechanism.

The postulated mechanism has been shown below (Fig. 4). It is proposed that the reaction is started with the abstraction of a proton from $\beta$-naphthol and the subsequent knoevenagel condensation occurs. In the next step, a Michael addition of malononitrile happens and with the final cyclization, the product is prepared.

\section{EXPERIMENTAL}

\section{General}

All commercially available chemicals were purchased from Fluka and Merck companies and used without further purification. Products were characterized by their physical constant and comparison with authentic samples. Reaction monitoring was accomplished by TLC on silica gel polygram SILG/UV 254 plates. The IR spectra were recorded on a BOMEM MB-Series 1998 FT-IR spectrophotometer using $\mathrm{KBr}$ pellets for the samples and the catalyst in the range of $4000-400 \mathrm{~cm}^{-1}$. ${ }^{1} \mathrm{H}$ and ${ }^{13} \mathrm{C}$ NMR spectra were recorded in $\mathrm{CDCl}_{3}$ and DMSO- $d_{6}$ on a Bruker Advanced DPX $400 \mathrm{MHz}$ spectrometer using TMS as internal standard. The SEM analyses were carried out using a LEO 1455VP Scanning
Electron Microscope, operating at 1-30 KV. Thermal stability of the supported catalyst was examined by BÄHR, SPA 503 Thermo-gravimetric Analyzer (TGA) at heating rate of $10{ }^{\circ} \mathrm{C} \mathrm{min}^{-1}$ over the temperature range of $40-700{ }^{\circ} \mathrm{C}$.

\section{General procedure for the preparation} of (n-prpyltrimethoxy silane)-4,4'-bipyridinium chloride (PTBPCI)

PTBPCl was prepared according to Arenas et al. ${ }^{6}$ with some modification. In a $50 \mathrm{~mL}$ RBF, $1.24 \mathrm{~g}(8 \mathrm{mmol}) 4,4^{\prime}-$ bipyridine was dissolved in $5 \mathrm{~mL}$ of DMF, afterwards $8 \mathrm{mmol}$ 3 -chloropropyl trimethoxy silane was added dropwise. The mixture was stirred at $90^{\circ} \mathrm{C}$ under Argon atomosphere for 72 hours. Finally, the precipitate was filtered and washed with methanol and dried at $90^{\circ} \mathrm{C}$ for 2 hours.

\section{General procedure for the preparation of RHPrBPCI}

In a $500 \mathrm{~mL} \mathrm{RBF}, 3 \mathrm{~g}$ of rice-husk nanosilica, was dissolved in $350 \mathrm{~mL}$ of $1 \mathrm{M} \mathrm{NaOH}$ for 24 hours. Afterwards the mixture was filtered to remove any residue. Then $2 \mathrm{~g}$ of PTBPCl was added to the filterate. The $\mathrm{pH}$ of this solution was adjusted to $\mathrm{pH}=5.0$ by addition of $3.0 \mathrm{M} \mathrm{HNO}_{3}$ solution. In this case, the solution was aged for 24 hours. Subsequently the precipitate was filtered and washed repeatedly with water and at last with acetone. The obtained silica was dried at $60{ }^{\circ} \mathrm{C}$ for 24 hours. 


\section{General procedure for the preparation of spirooxindole pyran derivatives in the presence of $\mathrm{RHPrBPCl}$ in water}

A $50 \mathrm{~mL}$ RBF was charged with isatin (1 mmol), malononitrile (1.2 mmol), 1,3-dicarbonyl compound, (dimedone, 4-hydroxy coumarine, $\alpha$-naphthol, $\beta$-naphthol or 4-hydroxy-6methyl-2-pyrone) $(1 \mathrm{mmol}), \mathrm{RHPrBPCl}(0.01 \mathrm{~g})$ and $10 \mathrm{~mL}$ deionized water. The mixture was refluxed in an oil-bath for specific time (10-15 min). Completion of the reaction was indicated by TLC [TLC n-hexane/ethyl acetate (1:1)]. After completion of the reaction (as indicated in Scheme 3), the mixture was filtered. The solid was washed with $15 \mathrm{~mL}$ hot ethanol to dissolve the product. The products were recrystallized in ethanol again.

\section{General procedure for the preparation of 2-amino-4H-chromene derivatives in the presence of RHPrBPCl in water}

A $50 \mathrm{~mL}$ RBF was charged with aromatic aldehydes (1 mmol), malononitrile (1.2 mmol), $\alpha$-naphthol, or $\beta$-naphthol $(1 \mathrm{mmol}), \mathrm{RHPrBPCl}(0.01 \mathrm{~g})$ and $10 \mathrm{~mL}$ deionized water. The mixture was refluxed in an oil-bath for specific time (8$35 \mathrm{~min})$. Completion of the reaction was indicated by TLC [TLC n-hexane/ethyl acetate (1:1)]. After completion of the reaction (as indicated in Table 2), the mixture was filtered. The solid was washed with $15 \mathrm{~mL}$ hot ethanol to dissolve the product. The products were recrystallized in ethanol again.

\section{CONCLUSION}

A novel rice-husk-silica supported n-propyl bipyridinium chloride (RHPrBPCl) with dual feature of being ionic liquid and basic catalyst, was prepared and utilized in the one-pot preparation of spirooxindole pyran and 2-amino-4H-chromene derivatives. The catalyst was characterized with FT-IR, SEM, and TGA analyses. This methodology offers several advantages including easy work-up procedure, high yields of the products, short reaction times, recyclable catalyst, and green reaction medium.

Acknowledgements. We are grateful to the Research Council of Shahid Chamran University for financial support.

\section{REFERENCES}

1. J. Zhu and H. Bienayme (Eds.), "Multicomponent Reactions", WILEY-VCH Verlag GmbH \& Co. KGaA, Weinheim, 2005.

2. A. Dömling, W. Wang and K. Wang, Chem. Rev., 2012, 112, 3083-3135.

3. A. R. Kiasat, H. Almasi and S. J. Saghanezhad, Rev. Roum. Chim., 2014, 59, 61-66.

4. A. R. Kiasat, M. Javaherian, M. Daei and M. Farbod, Rev. Roum. Chim., 2015, 60, 875-880.

5. G. P. Ellis, "The Chemistry of Heterocyclic Compounds Chromenes, Chromanes and Chromones", A. Weissberger and E. C. Taylor (Eds.), John Wiley: New York, 1977.
6. M. M. Khafagy, A. H. F. A. El-Wahas, F. A. Eid and A. M. El-Agrody, Farmaco., 2002, 57, 715-722.

7. K. Hiramoto, A. Nasuhara, K. Michiloshi, T. Kato and K. Kikugawa, Mutat. Res., 1997, 395, 47-56.

8. W. P. Smith, L. S. Sollis, D. P. Howes, C. P. Cherry, D. I. Starkey and N. K. Cobley, J. Med. Chem. 1998, 41, 787797.

9. C. P. Dell and C. W. Smith, European Patent Appl. EP537949, Chem. Abstr.,1993, 119, 139102d.

10. G. Bianchi and A. Tava, Agric. Biol. Chem., 1987, 51, 2001-2002.

11. S. J. Mohr, M. A. Chirigos, F. S. Fuhrman and J. W. Pryor, Cancer Res., 1975, 35, 3750-3754.

12. F. Eiden and F. Denk, Arch. Pharm. Weinheim Ger. (Arch. Pharm.), 1991, 324, 353-354.

13. R. J. Sundberg, "The Chemistry of Indoles", Academic: New York, NY, 1996.

14. A. H. Abdel-Rahman, E. M. Keshk, M. A. Hanna and Sh. M. El-Bady, Bioorg. Med. Chem., 2004, 12, 2483-2488.

15. A. Dandia, R. Singh, S. Khaturia, C. Merienne, G. Morgant and A. Loupy, Bioorg. Med. Chem., 2006, 14, 2409-2417.

16. B. Yu,D. Q. Yu and H. M. Liu, Eur. J. Med. Chem., 2015, 97, 673-698.

17. R. Ghahremanzadeh, Z. Rashid, A.-H. Zarnani and H. Naeimi, J. Ind. Eng. Chem., 2014, 20, 4076-4084.

18. G. S. Hari and Y. R. Lee, Synthesis 2010, 453-464.

19. Y. Li, H. Chen, C. Shi, D. Shi and S. Ji, J. Comb. Chem., 2010, 12, 231-237.

20. G. Shanthi, G. Subbulakshmi and P. T. Perumal, Tetrahedron, 2007, 63, 2057-2063.

21. L.-M. Wang, N. Jiao, J. Qiu, J.-J. Yu, J.-Q. Liu, F.-L. Guo and Y. Liu, Tetrahedron, 2010, 66, 339-343.

22. A. Mobinikhaledi, N. Foroughifar and M. A. B. Fard, Synth. Commun., 2011, 41, 441-450.

23. M. Kidwai, A. Jahan and N. K. Mishra, Appl. Catal. A.: Gen., 2012, 425-426, 35-43.

24. K. Rad-Moghadam and L. Youseftabar-Miri, Tetrahedron, 2011, 67, 5693-5699.

25. W.-B. Chen, Z.-J. Wu, Q.-L. Pei, L.-F. Cun, X.-M. Zhang and W.-C. Yuan, Org. Lett., 2010, 12, 3132-3135.

26. T. S. Jin, J. C. Xiao, S. J. Wang and T. S. Li, Ultrason. Sonochem., 2004, 11, 393-397.

27. T. S. Jin, J. S. Zhang, L. B. Liu, A. Q. Wang and T. S. Li, Synth. Commun., 2006, 36, 2009-2015.

28. M. Al-Matar, K. D. Khalil, H. Meier, H. Kolshorn and M. H. Elnagdi, Arkivoc, 2008, xvi, 288-301.

29. Z. Zhou, F. Yang,; L. Wu and A. Zhang, Chem. Sci. Trans., 2012, 1, 57-60.

30. M. Kidwai, S. Saxena, M. K. Rahman Khan and S. S. Thukral, Bioorg. Med. Chem. Lett., 2005, 15, 4295-4298.

31. M. R. Naimi-jamal, S. Mashkouri and A. Sharifi, Mol. Divers., 2010, 14, 473-477.

32. D. Kumar, V. B. Reddy, G. B. Mishra, R. K. Rann, M. N. Nadagouda and R. S. Varma, Tetrahedron, 2007, 63, 3093-3097.

33. M. M. Heravi, K. Bakhtiari, V. Zadsirjan and F. F. Bamoharram, Bioorg. Med. Chem.Lett., 2007, 17, 42624265.

34. B. S. Kumar, N. Shrinvasulu, R. H. Udupi, B. Rajitha, Y. T. Reddy, P. N. Reddy and P. S. Kumar, J. Heterocycl. Chem., 2006, 43, 1691-1693. 
35. M. M. Heravi, B. Baghernejad and H. A. Oskooie, J. Chin. Chem. Soc., 2008, 55, 659-662.

36. K. Rad-Moghadam and L. Yoseftabar-Miri, Tetrahedron, 2011, 67, 5693-5699.

37. M. J. Khurana, B. Nand and P. Saluja, Tetrahedron, 2010, 66, 5637-5641.
38. D. S. Raghuvanshi and K. N. Singh, Arkivoc, 2010, 10, 305-317.

39. A. R. Kiasat, S. Nazari and J. Davarpanah, C. R. Chimie, 2014, 17, 124-130.

40. A. R. Kiasat, A. Mouradzadegun and S. J. Saghanezhad, Chin. J. Catal., 2013, 34, 1861-1868. 